\title{
Combined television viewing and computer use and mortality from all-causes and diseases of the circulatory system among adults in the United States
}

\author{
Earl S Ford ${ }^{1,2}$
}

\begin{abstract}
Background: Watching television and using a computer are increasingly common sedentary behaviors. Whether or not prolonged screen time increases the risk for mortality remains uncertain.

Methods: Mortality for 7,350 adults aged $\geq 20$ years who participated in the National Health and Nutrition Examination Survey during 1999-2002 and were followed through 2006 was examined. Participants were asked a single question about the amount of time they spent watching television or videos or using a computer during the past 30 days.

Results: During a median follow-up of 5.8 years, 542 participants died. At baseline, 12.7\% of participants reported watching television or using a computer less than $1 \mathrm{~h}$ per day, $16.4 \%$ did so for $1 \mathrm{~h}, 27.8 \%$ for $2 \mathrm{~h}, 18.7 \%$ for $3 \mathrm{~h}$, $10.9 \%$ for $4 \mathrm{~h}$, and $13.5 \%$ for 5 or more $\mathrm{h}$. After extensive adjustment, the hazard ratio for all-cause mortality for the top category of exposure was 1.30 (95\% confidence interval: 0.82, 2.05). No significant trend across categories of exposure was noted. The amount of screen time was also not significantly related to mortality from diseases of the circulatory system.
\end{abstract}

Conclusions: In the present study, screen time did not significantly predict mortality from all-causes and diseases of the circulatory system.

Keywords: Mortality, Sedentary lifestyle, Television

\section{Background}

During the first quarter of 2010, the typical American watched over $35 \mathrm{~h}$ of television per week as well as over 2 $\mathrm{h}$ of time shifted television and used the internet for almost $4 \mathrm{~h}[1]$. According to the 2010 American Time Use Survey, people aged $\geq 15$ years watched television an average of $2.7 \mathrm{~h}$ per day making it the most common leisure activity [2]. Of some concern is that the amount of television viewing has been drifting steadily upwards [1].

Excessive amounts of watching television have been linked in cross-sectional as well as prospective studies to

Correspondence: eford@cdc.gov

${ }^{1}$ Division of Adult and Community Health, National Center for Chronic Disease Prevention and Health Promotion, Centers for Disease Control and Prevention, Atlanta, GA, USA

Full list of author information is available at the end of the article obesity, insulin resistance, metabolic syndrome, diabetes, and other conditions [3-11]. Because of the epidemics of obesity and diabetes and the possible contribution of excessive television viewing to these conditions, curtailing the quantity of television viewing among children has become a Healthy People 2020 objective [12].

Several studies have examined the links between television watching and mortality from all-causes and cardiovascular disease [13-16]. A meta-analysis of this set of studies found that prolonged screen time was modestly associated with an increased risk of all-cause mortality (adjusted hazard ratio [aHR] per $2 \mathrm{~h}$ of television viewing per day $=1.13,95 \%$ confidence interval $[\mathrm{CI}]=1.07$, 1.18) and fatal or nonfatal cardiovascular disease (aHR per $2 \mathrm{~h}$ of television viewing per day $=1.15,95 \% \mathrm{CI}=$ $1.06,1.23)$. Only one of these studies was conducted in 
the United States and included a selective sample of men [14]. Because watching television and using a computer are such common sedentary behaviors, a thorough understanding about the possible links between the amount of time that people spent watching television or using computers is critical to developing sound recommendations about these sedentary behaviors. Consequently, the objective of this study was to examine the relationship between the time spent watching television or videos and using computers outside of work and mortality in a population-based sample of adults in the United States.

\section{Methods}

This study was based on data from the public files for the 2006 follow-up of participants of the 1999-2000 and 2001-2002 cycles of the National Health and Nutrition Examination Survey (NHANES). A multistage, stratified sampling design was used to generate a sample of participants who were representative of the non institutionalized civilian US population. The response rates for the interviewed and examined samples of the entire survey were $82 \%(9965 / 12160)$ and $76 \%(9282 / 12160)$, respectively, for $1999-2000$ and $84 \%(11039 / 13156)$ and $80 \%$ (10477/13156), respectively, for 2001-2002. After an interview at home, participants were invited to complete additional questionnaires, undergo a set of tests, and provide blood and other biological specimens in the mobile examination center. Methodological details about the NHANES and the linked mortality files have been published $[17,18]$. The National Center for Health Statistics Research Ethics Review Board granted approval for the conduct of the study, and participants were asked to sign an informed consent form.

The mortality status of participants aged $\geq 20$ years through 2006 was determined by using the National Death Index [18]. Several studies have shown that the National Death Index identifies over $90 \%$ of deaths [19-21]. Participants who were not deemed to have died as of December 31, 2006 were considered to be alive. The International Classification of Diseases, 10th Revision (ICD-10) codes I00-I99 were used to identify deaths from diseases of the circulatory system.

Participants were asked "Over the past 30 days, on a typical day how much time altogether did you spend on a typical day sitting and watching TV or videos or using a computer outside of work? Would you say...". Response options were none, less than $1 \mathrm{~h}, 1 \mathrm{~h}, 2 \mathrm{~h}, 3$ $\mathrm{h}, 4 \mathrm{~h}$, or $5 \mathrm{~h}$ or more. The time spent watching TV or videos or using a computer will also be referred to as screen time.

Study covariates included age, gender, race or ethnicity (white, African American, Mexican American, and other), educational attainment $(<$ high school, high school graduate or equivalent, $>$ high school), smoking status (current, former, never), leisure-time physical activity (continuous), Healthy Eating Index score (continuous), alcohol use (continuous), self-reported health status, health insurance coverage, histories of cardiovascular disease and cancer, body mass index, systolic blood pressure, and concentrations of high-density lipoprotein cholesterol, non-high-density lipoprotein cholesterol, and HbA1c. Participants who had smoked 100 cigarettes during their lifetime and reported smoking at the time of the interview were classified as current smokers. Participants who had smoked 100 cigarettes during their lifetime and reported not smoking at the time of the interview were classified as former smokers. Participants who had never smoked 100 cigarettes during their lifetime were classified as never smokers. Participants were asked about partaking in moderate and vigorous physical activities in leisure-time and, for those who did, the time spent being physically active was calculated from their responses to the frequency and duration of the reported moderate and vigorous activities with the time spent being vigorously active being weighted by a factor of 2. The Healthy Eating Index is a score that ranges from 0 to 100 and has 10 subcomponents: grains, fruits, vegetables, dairy, meats, fats, saturated fat, cholesterol, sodium, and variety [22]. The index was determined from dietary information collected by a single 24$\mathrm{h}$ recall administered in person to participants attending the medical examination. The intake of alcohol was obtained from information provided during a single 24$\mathrm{h}$ dietary recall.

Self-reported health status was determined from the question "Would you say your health in general is excellent, very good, good, fair, or poor?". Health insurance coverage (yes/no) was derived from the question "Are you covered by health insurance or some other kind of health care plan?". Participants who reported ever being told by a doctor or other health professional that they had congestive heart failure, coronary heart disease, angina pectoris, heart attack, or stroke were considered as having a history of cardiovascular disease. Participants who reported ever being told by a doctor or other health professional that they had diabetes were considered to have diabetes. Participants who reported ever being told by a doctor or other health professional that they had cancer were considered to have cancer.

Body mass index $\left(\mathrm{kg} / \mathrm{m}^{2}\right)$ was calculated from measured weight and height. Up to four attempts were made to measure blood pressure. The average of the last two measurements of blood pressure for participants who had three measurements, the last measurement for participants with only two measurements, and the only measurement for participants who had one measurement were used. Serum total cholesterol and high- 
density lipoprotein cholesterol were measured enzymatically on a Hitachi 704 Analyzer (Roche Diagnostics, Indianapolis, IN) at Johns Hopkins University. Nonhigh-density lipoprotein cholesterol was calculated by subtracting the concentration of high-density lipoprotein cholesterol from that of total cholesterol. Concentrations of HbA1c were measured on Primus Automated HPLC systems, models CLC330 and CLC385 (Primus Corp., Kansas City, MO) at the University of MissouriColumbia.

The analyses included participants who were aged $\geq 20$ years and nonpregnant women. Chi-square tests and ttests for independent samples were used to examine differences in percentages and means, respectively. The Cochran-Mantel-Haenzel test was used to test for differences in the distribution of categorical variables after stratification by age groups. Age-adjusted mortality rates per 1,000 person-years of follow-up were calculated. Ageadjustment was performed using the direct method with the projected year 2000 US population. Proportional hazards analysis was used to estimate hazard ratios. Using Schoenfeld residuals, the proportional hazards assumption was met. Several proportional hazards models were run that included varying sets of covariates selected from age, gender, race or ethnicity, educational attainment, smoking status, leisure-time physical activity, Healthy Eating Index score, alcohol use, self-reported health status, health insurance coverage, and histories of cardiovascular disease and cancer. The statistical softwares SAS and SUDAAN were used to generate the results.

\section{Results}

Of the 9,471 participants aged $\geq 20$ years who had an examination, 10 were ineligible for follow-up because the information needed to link to the National Death Index was lacking. Of the 9,448 participants who provided information about the amount of screen time, 7,350 participants who had complete data for all the study variables were included in the analyses.

After adjustment for age, $12.7 \%$ reported no or less than $1 \mathrm{~h}$ per day of screen time, $16.4 \%$ reported $1 \mathrm{~h}$, $27.8 \%$ reported $2 \mathrm{~h}, 18.7 \%$ reported $3 \mathrm{~h}, 10.9 \%$ reported $4 \mathrm{~h}$, and $13.5 \%$ reported 5 or more hours. The distributions of the proportions of adults watching television or using a computer differed by gender $(p=0.003)$ and by race or ethnicity $(P<0.001)$ (Figure 1$)$.

Participants were followed on average for 5.8 years during which time 542 deaths including 190 deaths from diseases of the circulatory system were recorded. The unweighted follow-up time of the cohort was 41,502 person-years. Decedents and survivors differed in a number of study variables (Table 1). As screen time increased, significant increases or decreases were noted for all covariates except for reporting a history of cancer and alcohol consumption (Table 2).

In the model that only adjusted for age, participants reporting 5 or more hours per day of screen time had significantly increased mortality (Table 3 ). With progressively increasing numbers of covariates, the adjusted hazard ratio decreased steadily. After adjusting for sociodemographic factors and lifestyle behaviors, the

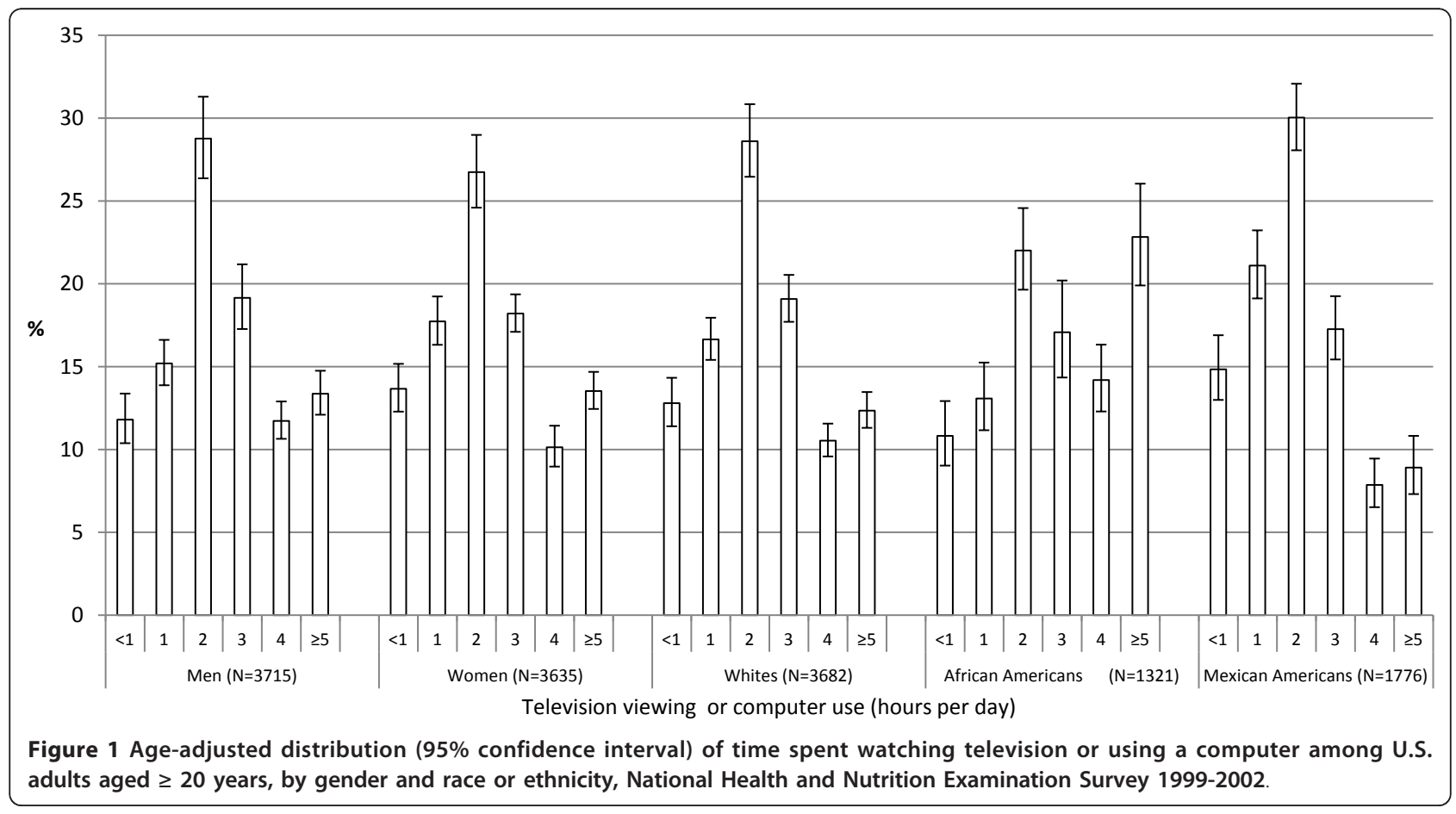


Table 1 Selected age-adjusted baseline characteristics among adults aged $>=20$ years, by mortality status, National Health and Nutrition Examination Survey 1999-2002

\begin{tabular}{|c|c|c|c|c|}
\hline & Total $(\mathrm{N}=7350)$ & Deceased $(\mathrm{N}=542)$ & Survivors $(\mathrm{N}=6808)$ & \\
\hline Characteristics & Mean or\% $(95 \% \mathrm{Cl})$ & Mean or\% $(95 \% \mathrm{Cl})$ & Mean or\% $(95 \% \mathrm{Cl})$ & $\mathbf{P}$ \\
\hline Age (years) & $45.3(44.6,46.0)$ & $66.9(64.7,69.0)$ & $44.3(43.6,45.0)$ & $<0.001$ \\
\hline Men, $\%$ & $49.2(48.1,50.2)$ & $64.3(51.5,75.3)$ & $48.6(47.4,49.7)$ & 0.013 \\
\hline Whites, $\%$ & $73.3(69.4,76.8)$ & $63.5(53.0,72.9)$ & $73.4(69.5,77.0)$ & 0.050 \\
\hline$>$ High school,\% & $53.1(50.2,56.0)$ & $32.2(23.1,42.9)$ & $53.7(50.8,56.6)$ & $<0.001$ \\
\hline Current smoker,\% & $24.1(22.2,26.1)$ & $33.7(23.9,45.1)$ & $23.5(21.6,25.6)$ & 0.075 \\
\hline Leisure-time physical activity (min/month) & $321.1(285.1,357.2)$ & $310.3(6.6,613.9)$ & $326.3(289.6,362.9)$ & 0.914 \\
\hline Alcohol intake (g) & $11.6(10.1,13.1)$ & $10.6(2.9,18.3)$ & $11.6(10.1,13.2)$ & 0.775 \\
\hline Healthy Eating Index score & $63.7(62.9,64.5)$ & $58.9(56.8,60.9)$ & $63.9(63.0,64.7)$ & $<0.001$ \\
\hline Body mass index $\left(\mathrm{kg} / \mathrm{m}^{2}\right)$ & $27.9(27.6,28.2)$ & $29.3(27.5,31.0)$ & $27.9(27.6,28.2)$ & 0.138 \\
\hline Systolic blood pressure $(\mathrm{mm} \mathrm{Hg})$ & $123.1(122.3,123.9)$ & $122.8(119.0,126.6)$ & $123.0(122.2,123.8)$ & 0.926 \\
\hline High-density lipoprotein cholesterol (mg/dl) & $50.9(50.1,51.7)$ & $46.5(43.7,49.3)$ & $50.9(50.2,51.7)$ & 0.002 \\
\hline Non-high-density lipoprotein cholesterol (mg/dl) & $152.2(150.0,154.3)$ & $167.3(147.1,187.4)$ & $151.9(149.8,154.1)$ & 0.130 \\
\hline $\mathrm{HbA1c}(\%)$ & $5.4(5.4,5.5)$ & $5.9(5.6,6.3)$ & $5.4(5.4,5.5)$ & 0.006 \\
\hline Excellent or very good health,\% & $54.7(52.5,56.9)$ & $33.3(24.8,43.2)$ & $55.8(53.6,58.0)$ & $<0.001$ \\
\hline Health insurance coverage, $\%$ & $82.6(80.8,84.4)$ & $80.4(68.7,88.4)$ & $82.8(80.9,84.5)$ & 0.637 \\
\hline Diagnosed diabetes, $\%$ & $6.3(5.7,7.1)$ & $16.1(10.8,23.2)$ & $5.9(5.1,6.8)$ & 0.003 \\
\hline History of cardiovascular disease, $\%$ & $8.3(7.5,9.3)$ & $26.3(17.7,37.3)$ & $7.4(6.6,8.4)$ & 0.001 \\
\hline History of cancer, $\%$ & $7.9(7.2,8.7)$ & $13.3(8.9,19.6)$ & $7.5(6.8,8.4)$ & 0.038 \\
\hline Screen time (hours per day) & & & & 0.025 \\
\hline$<1$ & $12.7(11.5,14.0)$ & $5.8(3.0,11.0)$ & $12.8(11.6,14.1)$ & \\
\hline 1 & $16.4(15.5,17.3)$ & $10.2(5.4,18.3)$ & $16.5(15.6,17.3)$ & \\
\hline 2 & $27.8(26.1,29.5)$ & $34.7(26.0,44.6)$ & $28.0(26.3,29.7)$ & \\
\hline 3 & $18.7(17.6,19.9)$ & $20.7(11.1,35.4)$ & $18.6(17.3,19.9)$ & \\
\hline 4 & $10.9(10.1,11.9)$ & $7.1(4.0,12.3)$ & $11.0(10.2,12.0)$ & \\
\hline$>=5$ & $13.5(12.6,14.4)$ & $21.5(13.8,32.0)$ & $13.1(12.3,14.1)$ & \\
\hline
\end{tabular}

attenuated hazard ratio still retained its statistical significance. Additional adjustment for health status, insurance coverage, and prevalent chronic conditions further attenuated the hazard ratio, and the confidence interval of the hazard ratio included the null. The aHR for screen time as a continuous variable adjusted for variables in model 5 in Table 3 was 1.03 per hour (95\% CI: 0.97, $1.10)$ or 1.07 per $2 \mathrm{~h}(95 \% \mathrm{CI}: 0.93,1.22)$ for all-cause mortality and 1.01 per hour $(95 \%$ CI: $0.88,1.15)$ or 1.02 per $2 \mathrm{~h}(95 \% \mathrm{CI}: 0.78,1.33)$ for mortality from diseases of the circulatory system. Adding several possible mediating variables (body mass index, systolic blood pressure, and concentrations of high-density lipoprotein cholesterol, non-high-density lipoprotein cholesterol, and $\mathrm{HbA1c}$ ) did not further attenuate the hazard ratios. Screen time was not significantly related to mortality from diseases of the circulatory system. To examine possible nonlinearity of screen time, a quadratic term was added to the model but proved to be nonsignificant ( $p=0.634$ for all-cause mortality, $p=0.903$ for diseases of the circulatory system).

Using model 4 as shown in Table 3 and screen time as a continuous variable, no effect modification by age $(<65$ years versus $>=65$ years) $(p=0.469$ for mortality from diseases of the circulatory system), gender ( $\mathrm{p}$ interaction $=0.809$ for all-cause mortality and $p=0.281$ for mortality from diseases of the circulatory system) or by race or ethnicity for the three major groups ( $p$ interaction $=0.721$ for all-cause mortality and $p=0.568$ for mortality from diseases of the circulatory system) was noted. However, the hazards ratios for all-cause mortality differed significantly for participants aged < 65 years (aHR: 1.11, 95\% CI: $1.00,1.23$ ) and $>=65$ years (aHR: $1.01,95 \%$ CI: 0.94, 1.08) ( $\mathrm{p}$ interaction $=0.036)$. A model that excluded participants who died during the first year (491 total deaths and 169 from diseases of the circulatory system among 7,342 participants) failed to show evidence of a significant association between screen time and all-cause mortality or diseases of the circulatory system.

Hazard ratios were also calculated for a reduced set of categories that are generally consistent with some previous studies (Table 4). The results did not show significant associations between screen time and mortality from all-causes or diseases of the circulatory system.

When participants with chronic conditions (diabetes, cardiovascular disease, and cancer) were excluded, the 
Table 2 Selected age-adjusted baseline characteristics among adults aged $>=20$ years, by level of screen time, National Health and Nutrition Examination Survey 1999-2002

\begin{tabular}{|c|c|c|c|c|c|c|c|}
\hline \multirow[b]{3}{*}{ Characteristics } & \multicolumn{7}{|c|}{ Screen time (hours per day) } \\
\hline & $<1$ & 1 & 2 & 3 & 4 & $>=5$ & \\
\hline & $\begin{array}{l}\text { Mean or\% } \\
(95 \% \mathrm{Cl})\end{array}$ & $\begin{array}{l}\text { Mean or\% } \\
(95 \% \mathrm{Cl})\end{array}$ & $\begin{array}{l}\text { Mean or\% } \\
(95 \% \mathrm{Cl})\end{array}$ & $\begin{array}{l}\text { Mean or\% } \\
(95 \% \mathrm{Cl})\end{array}$ & $\begin{array}{l}\text { Mean or\% } \\
(95 \% \mathrm{Cl})\end{array}$ & $\begin{array}{l}\text { Mean or\% } \\
(95 \% \mathrm{Cl})\end{array}$ & $\begin{array}{l}P \text { for } \\
\text { trend }\end{array}$ \\
\hline Age (years) & $43.6(42.6,44.6)$ & $43.0(41.7,44.3)$ & $45.3(44.3,46.2)$ & $46.8(45.4,48.1)$ & $47.3(45.8,48.7)$ & $46.4(45.4,47.3)$ & $<0.001$ \\
\hline Men, $\%$ & $46.1(42.7,49.5)$ & $46.4(43.2,49.6)$ & $51.1(48.1,54.1)$ & $50.7(47.2,54.1)$ & $53.0(49.1,56.8)$ & $48.6(45.3,51.8)$ & 0.012 \\
\hline Whites, $\%$ & $72.9(67.3,78.0)$ & $74.1(69.8,78.0)$ & $75.3(70.7,79.4)$ & $74.7(69.9,79.0)$ & $71.0(66.1,75.5)$ & $67.0(62.3,71.4)$ & 0.013 \\
\hline$>$ High school, $\%$ & $58.9(55.4,62.4)$ & $58.4(53.7,63.1)$ & $54.0(50.1,57.9)$ & $52.1(47.6,56.5)$ & $47.7(42.4,53.2)$ & $43.2(39.7,46.7)$ & $<0.001$ \\
\hline Current smoker,\% & $19.6(15.6,24.2)$ & $16.5(13.4,20.2)$ & $22.1(19.0,25.6)$ & $29.2(25.6,33.1)$ & $29.1(26.4,31.8)$ & $35.0(31.6,38.5)$ & $<0.001$ \\
\hline $\begin{array}{l}\text { Leisure-time physical activity (min/ } \\
\text { month) }\end{array}$ & $\begin{array}{l}443.2(319.6 \\
566.8)\end{array}$ & $\begin{array}{l}336.3(276.6 \\
396.0)\end{array}$ & $\begin{array}{l}337.8(296.4 \\
379.1)\end{array}$ & $\begin{array}{l}323.2(272.0 \\
374.4)\end{array}$ & $\begin{array}{l}257.0(207.2 \\
306.9)\end{array}$ & $\begin{array}{l}198.8(165.1 \\
232.5)\end{array}$ & 0.043 \\
\hline Alcohol intake (g) & $10.2(7.9,12.4)$ & $12.0(9.5,14.5)$ & $12.0(9.4,14.6)$ & $10.4(8.7,12.0)$ & $13.0(9.3,16.7)$ & $12.8(8.4,17.3)$ & 0.881 \\
\hline Healthy Eating Index score & $65.4(64.2,66.6)$ & $65.2(64.1,66.4)$ & $64.1(62.9,65.3)$ & $62.6(61.6,63.5)$ & $63.4(61.9,64.8)$ & $60.9(59.9,61.9)$ & $<0.001$ \\
\hline Body mass index $\left(\mathrm{kg} / \mathrm{m}^{2}\right)$ & $26.5(26.0,27.0)$ & $27.2(26.6,27.9)$ & $27.8(27.4,28.2)$ & $28.0(27.4,28.7)$ & $29.4(28.8,30.1)$ & $28.9(28.3,29.5)$ & $<0.001$ \\
\hline Systolic blood pressure $(\mathrm{mm} \mathrm{Hg})$ & $\begin{array}{l}121.8(120.5 \\
123.1)\end{array}$ & $\begin{array}{l}122.5(121.3 \\
123.8)\end{array}$ & $\begin{array}{l}122.9(121.8 \\
124.0)\end{array}$ & $\begin{array}{l}123.7(122.5 \\
124.9)\end{array}$ & $\begin{array}{l}124.9(123.0 \\
126.8)\end{array}$ & $\begin{array}{l}124.4(122.9 \\
125.8)\end{array}$ & 0.007 \\
\hline $\begin{array}{l}\text { High-densit } \\
\text { cholesterol }\end{array}$ & $3.0(52.0,53.9)$ & $52.3(50.7,53.8)$ & $50.9(49.7,52.0)$ & $50.4(49.3,51.6)$ & $50.0(48.1,51.9)$ & $48.9(47.4,50.4)$ & 0.001 \\
\hline $\begin{array}{l}\text { Non-high-density lipoprotein } \\
\text { cholesterol (mg/dl) }\end{array}$ & $\begin{array}{l}147.3(143.6, \\
150.9)\end{array}$ & $\begin{array}{l}149.7(146.1 \\
153.3)\end{array}$ & $\begin{array}{l}153.7(150.8, \\
156.6)\end{array}$ & $\begin{array}{l}153.8(150.7 \\
156.9)\end{array}$ & $\begin{array}{l}153.0(149.0, \\
156.9)\end{array}$ & $\begin{array}{l}155.0(151.8 \\
158.2)\end{array}$ & 0.001 \\
\hline $\mathrm{HbA1c}(\%)$ & $5.4(5.3,5.4)$ & $5.4(5.4,5.5)$ & $5.4(5.4,5.5)$ & $5.5(5.4,5.5)$ & $5.5(5.4,5.6)$ & $5.6(5.5,5.7)$ & 0.039 \\
\hline Excellent or very good health,\% & $62.7(59.5,65.9)$ & $60.7(54.9,66.2)$ & $57.1(54.1,60.0)$ & $53.5(50.2,56.8)$ & $44.2(39.5,49.0)$ & $42.8(38.6,47.2)$ & $<0.001$ \\
\hline Health insurance coverage, $\%$ & $83.7(80.4,86.5)$ & $84.0(80.6,86.9)$ & $84.9(82.5,87.1)$ & $82.0(79.7,84.1)$ & $81.5(77.5,84.8)$ & $75.7(71.7,79.3)$ & 0.001 \\
\hline Diagnosed diabetes, $\%$ & $5.1(3.6,7.2)$ & $4.8(3.3,6.8)$ & $5.7(4.7,6.7)$ & $7.1(5.4,9.2)$ & $7.2(5.8,8.8)$ & $9.4(7.4,11.9)$ & 0.001 \\
\hline History of cardiovascular disease, $\%$ & $6.5(4.8,8.7)$ & $7.4(5.9,9.3)$ & $7.7(6.3,9.3)$ & $7.9(6.8,9.2)$ & $7.4(6.1,8.8)$ & $14.8(12.7,17.3)$ & $<0.001$ \\
\hline History of cancer, $\%$ & $7.1(5.1,9.6)$ & $7.1(5.1,9.8)$ & $7.5(6.3,8.9)$ & $8.6(7.1,10.5)$ & $7.4(5.7,9.6)$ & $9.6(7.5,12.3)$ & 0.159 \\
\hline
\end{tabular}

hazard ratios were only slightly lower (Table 5). The maximally-adjusted model for deaths from diseases of the circulatory system suggested a trend of increasing risk with increasing screen time. Because of the limited number of deaths, however, the estimates should be cautiously interpreted.

\section{Discussion}

Like other studies, the present study found that U.S. adults spent considerable time watching television or videos or using a computer. However, the present study offers little support for the hypothesis that prolonged screen time may increase mortality from all-causes and diseases of the circulatory system. Furthermore, control for confounding may be a particularly challenging issue in studies of screen time and mortality.

Previous prospective studies have reported variable findings about the relationship between the amount of television watching and mortality [13-16]. In an analysis of data from the Aerobics Center Longitudinal Study, 7744 men were followed for 21 years during which time 377 men died from cardiovascular disease [14]. The hours per week of screen time were divided into quartiles. After adjusting for age, smoking, alcohol use, family history of cardiovascular disease, body mass index, physical activity, and self-reported hypertension, diabetes, and hypercholesterolemia, screen time was not significantly related to mortality from cardiovascular disease (quartile $2: \mathrm{HR}=1.02,95 \% \mathrm{CI}=0.74,1.42$; quartile $3: \mathrm{HR}=1.27,95 \% \mathrm{CI}=0.90,1.78$; quartile $4: \mathrm{HR}=0.96$, $95 \% \mathrm{CI}=0.68,1.36$; $\mathrm{p}$ for trend $=0.94$ ).

In the Australian Diabetes, Obesity, and Lifestyle Study, 8800 adults aged $\geq 25$ years were followed on average for 6.6 years during which time 284 participants died (87 from cardiovascular disease) [13]. Compared to adults who watched television $<2 \mathrm{~h}$ /day, those watching $2-<4 \mathrm{~h} /$ day, and 4 or more hours per day had a significantly increased risk for mortality from all-causes ( $\mathrm{HR}=$ $1.13,95 \% \mathrm{CI}=0.87,1.36$; $\mathrm{HR}=1.46,95 \% \mathrm{CI}=1.04$, 2.05 , respectively) and cardiovascular disease $(\mathrm{HR}=$ $1.19,95 \% \mathrm{CI}=0.72,1.99 ; \mathrm{HR}=1.80,95 \% \mathrm{CI}=1.00$, 3.25 , respectively). The hazard ratios were adjusted for age, gender, education, smoking status, energy intake, alcohol use, diet quality index, waist circumference, hypertension, total cholesterol, high-density lipoprotein cholesterol, triglycerides, lipid-lowering medications, and glucose tolerance status.

In the European Prospective Investigation into Cancer and Nutrition Norfolk Study, 13,197 men and women with a mean age of 61.5 years were followed for a mean 
Table 3 Sample sizes, rates, and hazard ratios for mortality from all-causes and diseases of the circulatory system among participants aged $>=20$ years, National Health and Nutrition Examination Survey 1999-2002-2006

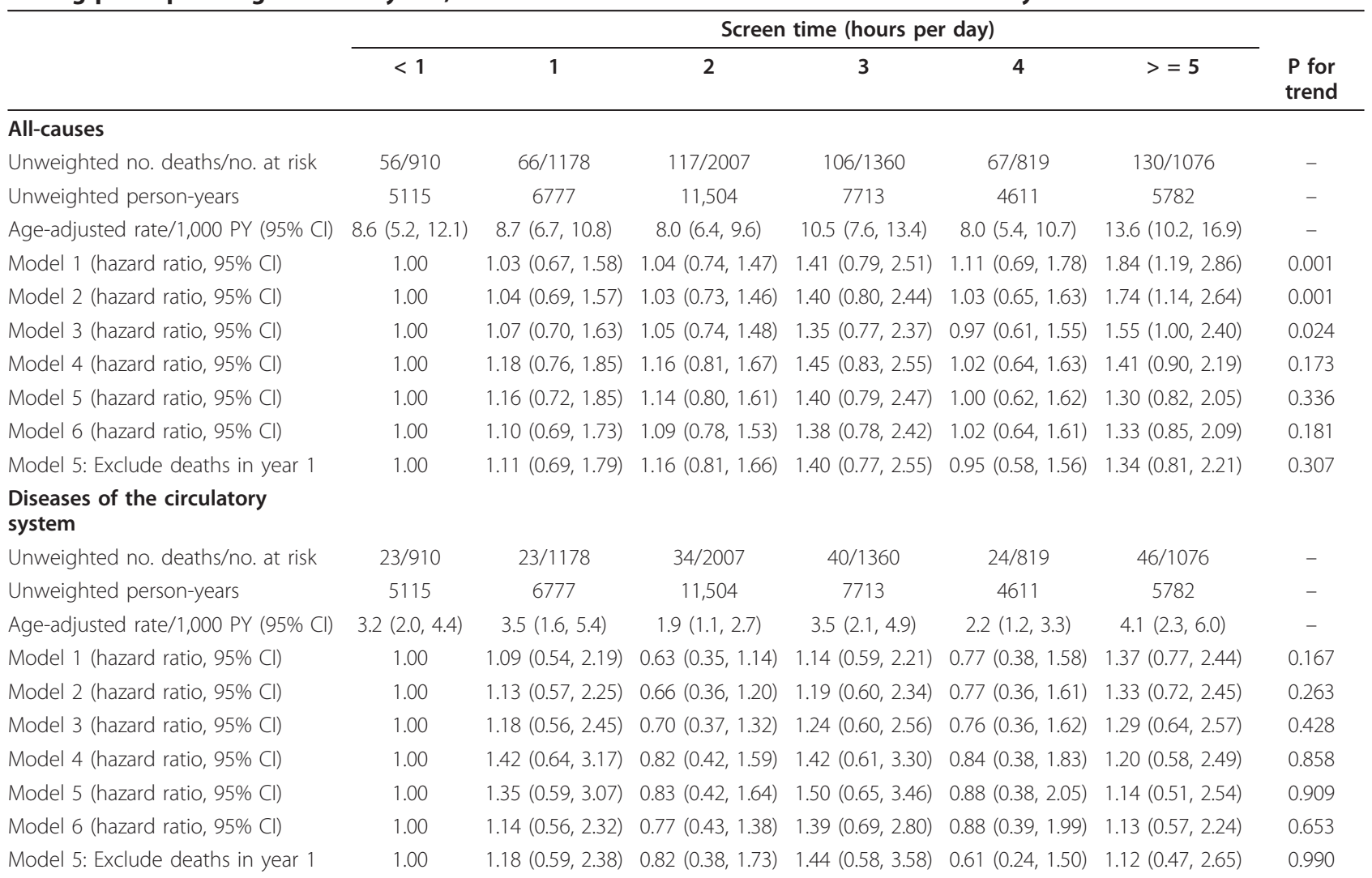

$\mathrm{Cl}=$ confidence interval; $P Y=$ person-years

Model 1 is adjusted for age

Model 2 is adjusted for age, gender, race or ethnicity, educational attainment

Model 3 is adjusted for variables in model 2 plus smoking status, leisure-time physical activity, Healthy Eating Index score, and alcohol consumption

Model 4 is adjusted for variables in model 3 plus health status and health insurance coverage

Model 5 is adjusted for variables in model 4 plus histories of diabetes, cardiovascular disease, and cancer

Model 6 is adjusted for variables in model 5 plus body mass index, systolic blood pressure, and concentrations of high-density lipoprotein cholesterol, non-highdensity lipoprotein cholesterol, and $\mathrm{HbA} 1 \mathrm{c}$

of 9.5 years and 1270 participants died (373 from cardiovascular disease) [16]. After adjusting for age, gender, education, smoking status, alcohol use, medications for hypertension and dyslipidemia, history of diabetes, family history of CVD and cancer, and physical activity, the hazard ratio per hour/day of watching television was 1.05 (95\% CI: 1.01, 1,09) for all-cause mortality and 1.08 (95\% CI: 1.01, 1.16) per hour/day for mortality from cardiovascular disease.

Recently, a fourth prospective study using data from the Scottish Health Survey was published [15]. During a mean follow-up of 4.3 years, 325 deaths (215 CV deaths) occurred among 4,512 men and women aged $\geq 35$ years. Compared to participants who watched television, used a computer, or played video games $<2 \mathrm{~h}$ per day, increased risks for all-cause mortality and fatal and nonfatal diseases of the circulatory system were noted for those who did so for $2-<4 \mathrm{~h}$ per day (all-cause mortality aHR $=1.14,95 \% \mathrm{CI}=0.80-1.62$; diseases of the circulatory system $\mathrm{aHR}=2.2395 \% \mathrm{CI}=1.31-3.80$ ) and $\geq 4$ h per day (all-cause mortality aHR $=1.48,95 \%$ $\mathrm{CI}=1.04-2.13$; diseases of the circulatory system $\mathrm{aHR}=$ $2.2595 \% \mathrm{CI}=1.30-3.89)$. The risk estimates were adjusted for age, gender, ethnicity, body mass index, smoking, social class, long-standing illness, marital status, diagnosed diabetes and hypertension, occupational physical activity, and physical activity.

Of the four studies, including the present study, that examined the associations between screen time and allcause mortality, only the present study failed to produce a significant association. Nevertheless, the adjusted hazard ratio of 1.31 in the present study for participants reporting $\geq 5 \mathrm{~h}$ per day of screen time is not inconsistent with the published estimates of screen time discussed above. The reasons for the dissonant findings are not entirely clear. All four studies used self-reported 
Table 4 Sample sizes, rates, and hazard ratios for mortality from all-causes and diseases of the circulatory system among participants aged > 20 years, National Health and Nutrition Examination Survey 1999-2002-2006

\begin{tabular}{|c|c|c|c|c|}
\hline & \multicolumn{4}{|c|}{ Screen time (hours per day) } \\
\hline & $<2$ & $2-<4$ & $>=4$ & $P$ for trend \\
\hline \multicolumn{5}{|l|}{ All-causes } \\
\hline Unweighted no. deaths/no. at risk & $122 / 2088$ & $223 / 3367$ & 197/1895 & - \\
\hline Unweighted person-years & 11,892 & 19,218 & 10,393 & - \\
\hline Age-adjusted rate/1,000 PY (95\% Cl) & $8.7(6.4,10.9)$ & $9.1(7.5,10.7)$ & $11.0(8.8,13.2)$ & - \\
\hline Model 1 (hazard ratio, 95\% Cl) & 1.00 & $1.18(0.87,1.60)$ & $1.47(1.15,1.89)$ & 0.003 \\
\hline Model 2 (hazard ratio, 95\% Cl) & 1.00 & $1.17(0.86,1.58)$ & $1.37(1.09,1.73)$ & 0.014 \\
\hline Model 3 (hazard ratio, 95\% Cl) & 1.00 & $1.14(0.84,1.55)$ & $1.24(0.96,1.59)$ & 0.134 \\
\hline Model 4 (hazard ratio, 95\% Cl) & 1.00 & $1.18(0.87,1.59)$ & $1.13(0.88,1.44)$ & 0.712 \\
\hline Model 5 (hazard ratio, 95\% Cl) & 1.00 & $1.16(0.86,1.55)$ & $1.08(0.85,1.38)$ & 0.962 \\
\hline Model 6 (hazard ratio, 95\% Cl) & 1.00 & $1.16(0.86,1.56)$ & $1.14(0.90,1.44)$ & 0.589 \\
\hline Model 4: Exclude prevalent diabetes, cardiovascular disease, cancer & 1.00 & $1.15(0.69,1.92)$ & $0.96(0.63,1.47)$ & 0.406 \\
\hline Model 5: Exclude deaths in year 1 & 1.00 & $1.20(0.89,1.61)$ & $1.11(0.86,1.42)$ & 0.917 \\
\hline \multicolumn{5}{|l|}{ Diseases of the circulatory system } \\
\hline Unweighted no. deaths/no. at risk & $46 / 2088$ & $74 / 3367$ & 70/1895 & - \\
\hline Unweighted person-years & 11,892 & 19,218 & 10,393 & - \\
\hline Age-adjusted rate/1,000 PY (95\% Cl) & $3.3(2.0,4.6)$ & $2.7(1.8,3.5)$ & $3.2(2.4,4.1)$ & - \\
\hline Model 1 (hazard ratio, 95\% Cl) & 1.00 & $0.82(0.48,1.40)$ & $1.05(0.72,1.53)$ & 0.388 \\
\hline Model 2 (hazard ratio, 95\% Cl) & 1.00 & $0.84(0.48,1.46)$ & $1.00(0.68,1.48)$ & 0.606 \\
\hline Model 3 (hazard ratio, 95\% Cl) & 1.00 & $0.86(0.49,1.54)$ & $0.96(0.62,1.48)$ & 0.880 \\
\hline Model 4 (hazard ratio, 95\% Cl) & 1.00 & $0.90(0.50,1.64)$ & $0.87(0.55,1.36)$ & 0.578 \\
\hline Model 5 (hazard ratio, 95\% Cl) & 1.00 & $0.96(0.54,1.71)$ & $0.88(0.53,1.45)$ & 0.555 \\
\hline Model 6 (hazard ratio, 95\% Cl) & 1.00 & $0.98(0.56,1.71)$ & $0.96(0.60,1.52)$ & 0.845 \\
\hline Model 4: Exclude prevalent diabetes, cardiovascular disease, cancer & 1.00 & $1.07(0.46,2.47)$ & $1.65(0.75,3.62)$ & 0.186 \\
\hline Model 5: Exclude deaths in year 1 & 1.00 & $1.00(0.55,1.84)$ & $0.84(0.48,1.46)$ & 0.418 \\
\hline
\end{tabular}

$C l=$ confidence interval; $P Y=$ person-years

Model 1 is adjusted for age

Model 2 is adjusted for age, gender, race or ethnicity, educational attainment

Model 3 is adjusted for variables in model 2 plus smoking status, leisure-time physical activity, Healthy Eating Index score, and alcohol consumption

Model 4 is adjusted for variables in model 3 plus health status and health insurance coverage

Model 5 is adjusted for variables in model 4 plus histories of diabetes, cardiovascular disease, and cancer

Model 6 is adjusted for variables in model 5 plus body mass index, systolic blood pressure, and concentrations of high-density lipoprotein cholesterol, non-highdensity lipoprotein cholesterol, and $\mathrm{HbA1C}$

information to assess screen time although the questions in the studies differed. The follow-up times of the other three studies ranged from 4.3 years to 9.5 years compared to 5.8 years in the present study. Death status in all studies was determined through linkages to vital statistics.

Of the five studies, including the present one, that explored the associations between screen time and cardiovascular outcomes, two studies including the present one failed to report significant associations [14]. A meta-analysis of previous prospective studies of screen time and all-cause mortality and fatal or nonfatal cardiovascular disease estimated that the summary relative risk per $2 \mathrm{~h}$ of screen time per day was $1.13(95 \% \mathrm{CI}=1.07$, 1.18 ) for all-cause mortality and $1.15(95 \% \mathrm{CI}=1.06$, 1.23) for fatal or nonfatal cardiovascular disease [23]. Adding the results from the present study to the data shown in the meta-analysis changes the fixed-effects summary estimate of relative risk per $2 \mathrm{~h}$ of screen time to $1.12(95 \% \mathrm{CI}: 1.07,1.17$; test for heterogeneity $\mathrm{p}=$ $0.741)$ and 1.14 (95\% CI: 1.06, 1.22; test for heterogeneity $\mathrm{p}=0.736$ ), respectively. Thus, the totality of the current evidence continues to suggest that prolonged screen time poses a threat to health.

Several additional prospective studies examined the relationships between sedentary behavior, which included watching television in some studies, and mortality [24-26]. Although these three studies did not focus on screen time per se, they did find that excessive sedentary behavior, primarily in the form of sitting, showed a small increase in the risk of mortality from all-causes and cardiovascular disease.

Strengths of the study included the population-based sample that is representative of adults in the United 
Table 5 Sample sizes, rates, and hazard ratios for mortality from all-causes and diseases of the circulatory system among participants aged $>=20$ years after excluding prevalent self-reported diabetes, cardiovascular disease, and cancer, National Health and Nutrition Examination Survey 1999-2002-2006

\begin{tabular}{|c|c|c|c|c|c|c|c|}
\hline & \multicolumn{7}{|c|}{ Screen time (hours per day) } \\
\hline & $<1$ & 1 & 2 & 3 & 4 & $>=5$ & $\begin{array}{l}P \text { for } \\
\text { trend }\end{array}$ \\
\hline \multicolumn{8}{|l|}{ All-causes } \\
\hline Unweighted no. deaths/no. at risk & $21 / 744$ & $32 / 967$ & $48 / 1565$ & $46 / 1010$ & $22 / 611$ & $41 / 719$ & - \\
\hline Unweighted person-years & 4232 & 5617 & 9096 & 5843 & 3534 & 3963 & - \\
\hline Age-adjusted rate/1,000 PY (95\% Cl) & $5.4(1.1,9.6)$ & $5.9(3.0,8.9)$ & $5.0(3.8,6.1)$ & $8.1(5.3,10.8)$ & $4.1(2.1,6.2)$ & $8.6(5.8,11.5)$ & - \\
\hline Model 1 (hazard ratio, 95\% Cl) & 1.00 & $1.04(0.46,2.34)$ & $1.02(0.48,2.14)$ & $1.62(0.63,4.12)$ & $0.80(0.33,1.94)$ & $1.85(0.86,3.98)$ & 0.051 \\
\hline Model 2 (hazard ratio, 95\% Cl) & 1.00 & $1.06(0.46,2.40)$ & $1.00(0.48,2.09)$ & $1.60(0.65,3.95)$ & $0.77(0.33,1.81)$ & $1.71(0.82,3.57)$ & 0.091 \\
\hline Model 3 (hazard ratio, 95\% Cl) & 1.00 & $1.08(0.48,2.45)$ & $0.98(0.48,2.01)$ & $1.49(0.61,3.64)$ & $0.72(0.30,1.72)$ & $1.45(0.69,3.06)$ & 0.325 \\
\hline Model 4 (hazard ratio, 95\% Cl) & 1.00 & $1.12(0.50,2.53)$ & $1.03(0.51,2.09)$ & $1.48(0.62,3.52)$ & $0.71(0.30,1.68)$ & $1.33(0.65,2.74)$ & 0.592 \\
\hline Model 5 (hazard ratio, 95\% Cl) & 1.00 & $1.11(0.49,2.53)$ & $1.01(0.49,2.08)$ & $1.47(0.62,3.50)$ & $0.70(0.30,1.64)$ & $1.29(0.63,2.64)$ & 0.634 \\
\hline \multicolumn{8}{|l|}{$\begin{array}{l}\text { Diseases of the circulatory } \\
\text { system }\end{array}$} \\
\hline Unweighted no. deaths/no. at risk & $6 / 744$ & $8 / 967$ & $10 / 1565$ & 15/1010 & 9/611 & $15 / 719$ & - \\
\hline Unweighted person-years & 4232 & 5617 & 9096 & 5843 & 3534 & 3963 & - \\
\hline Age-adjusted rate/1,000 PY (95\% Cl) & $1.1(0.1,2.2)$ & $1.1(0.0,2.2)$ & $0.6(0.0,1.4)$ & $2.3(0.7,3.9)$ & $1.3(0.4,2.3)$ & $3.5(1.0,6.1)$ & - \\
\hline Model 1 (hazard ratio, 95\% Cl) & 1.00 & $1.04(0.19,5.62)$ & $0.52(0.11,2.41)$ & $1.46(0.42,5.05)$ & $0.89(0.25,3.17)$ & $2.68(0.83,8.70)$ & 0.071 \\
\hline Model 2 (hazard ratio, 95\% Cl) & 1.00 & $1.05(0.19,5.74)$ & $0.57(0.12,2.73)$ & $1.58(0.45,5.50)$ & $0.96(0.27,3.43)$ & $2.58(0.80,8.32)$ & 0.074 \\
\hline Model 3 (hazard ratio, 95\% Cl) & 1.00 & $1.10(0.21,5.78)$ & $0.58(0.12,2.76)$ & $1.55(0.42,5.68)$ & $0.93(0.26,3.28)$ & $2.45(0.72,8.35)$ & 0.101 \\
\hline Model 4 (hazard ratio, 95\% Cl) & 1.00 & $1.22(0.22,6.96)$ & $0.67(0.14,3.15)$ & $1.77(0.50,6.33)$ & $1.07(0.29,3.93)$ & $2.58(0.75,8.82)$ & 0.081 \\
\hline Model 5 (hazard ratio, 95\% Cl) & 1.00 & $1.47(0.24,8.81)$ & $0.75(0.16,3.42)$ & $2.04(0.54,7.70)$ & $1.43(0.34,6.07)$ & $3.17(0.86,11.63)$ & 0.042 \\
\hline \multicolumn{8}{|l|}{$\mathrm{Cl}=$ confidence interval; $\mathrm{PY}=$ person-years } \\
\hline \multicolumn{8}{|l|}{ Model 1 is adjusted for age } \\
\hline \multicolumn{8}{|c|}{ Model 2 is adjusted for age, gender, race or ethnicity, educational attainment } \\
\hline \multirow{2}{*}{\multicolumn{8}{|c|}{$\begin{array}{l}\text { Model } 3 \text { is adjusted for variables in model } 2 \text { plus smoking status, leisure-time physical activity, Healthy Eating Index score, and alcohol consumption } \\
\text { Model } 4 \text { is adjusted for variables in model } 3 \text { plus health status and health insurance coverage }\end{array}$}} \\
\hline \multicolumn{4}{|c|}{$\begin{array}{l}\text { Model } 4 \text { is adjusted for variables in model } 3 \text { plus health status and health insurance coverage } \\
\text { Model } 5 \text { is adjusted for variables in model } 5 \text { plus body mass index, systolic blood pressure, and concentrations of high-density lipoprotein cholesterc }\end{array}$} & & & & \\
\hline \multicolumn{8}{|c|}{$\begin{array}{l}\text { Model } 5 \text { is adjusted for variables in model } 5 \text { plus body mass index, systolic blood pressure, and concentrations of high-density lipoprotein cholesterol, non-high } \\
\text { density lipoprotein cholesterol, and HbA1c }\end{array}$} \\
\hline
\end{tabular}

States (excellent external validity), decent sample size, good response rates, and inclusion of a broad spectrum of potential confounding variables and of several potential cardiometabolic mediators that were objectively measured. However, these strengths deserve to be balanced against various limitations of the study. Like many other studies, the amount of screen time was selfreported. The questions used in the survey were not specifically validated for this study. However, selfreported screen time has been shown to correlate with other measures in expected ways and, in the present study, correlated as expected with a number of anthropometric and clinical variables. A review of the reliability and validity of self-reported television viewing and other sedentary behavior described acceptable reliability but variable validity [27].

Because the question or questions used to measure screen time constitute a critical aspect of the prospective studies, it is interesting to note that all prospective studies to date differ in their assessment of screen time. The Aerobics Center Longitudinal Study assessed average weekly time spent watching television [14]; the
Australian Diabetes, Obesity, and Lifestyle Study assessed total time spent watching television during the previous 7 days excluding time that the television was turned on but was not being watched [13]; the European Prospective Investigation into Cancer and Nutrition Norfolk Study asked about time spent watching television on weekdays and weekends [16]; and the Scottish Health Survey assessed the time spent watching television, using a computer, or playing video games on weekdays and weekends [15].

Consequently, some of the heterogeneity in the findings of the four studies examining the relationship between screen time and all-cause mortality and five studies of screen time and cardiovascular mortality might be attributable to the differences in questionnaires used to assess screen time. First, three of the previous studies assessed only the time spent watching television or watching videos $[13,14,16]$, whereas the third study, like the present one, assessed the time spent watching television, using a computer, or playing video games [15]. However, one of the first three studies failed to produce a significant association between screen time 
and cardiovascular disease whereas of the two studies that included time spent watching television, using a computer, or playing video games, one study reported a significant association [15] and the present study did not. Thus, it seems unlikely that this aspect of the questions about screen time explains the variation among studies. Nevertheless, the health effects of prolonged television viewing, which has been related to other unhealthy lifestyle behaviors notably unhealthy dietary elements, conceivably differ from those of prolonged use of a computer or playing video games.

Second, one study that reported significant associations between screen time and mortality from all-causes and cardiovascular disease attempted to limit screen time to the time that participants specifically watched television and not to the time that the television was turned on [13]. However, among the remaining four studies that did not involve this methodological twist, two studies produced positive findings for mortality from cardiovascular disease $[15,16]$, and two studies, including the present one, produced negative findings [14]. This aspect of the study questionnaires does not appear to readily explain the different findings of the studies.

Third, some studies measured screen time separately on weekdays and weekend days $[15,16]$ although not all studies were clear about this aspect of the exposure assessment. In the present study, screen time was not separately assessed for days during the week and weekend.

In the present study, participants reported sizeable amounts of screen time. The Nielsen Company data show that Americans spend on average about $35 \mathrm{~h}$ per week watching television, $2 \mathrm{~h}$ of time shifted television, and $4 \mathrm{~h}$ on the internet [1]. The self-reported data from the present study suggests that the most commonly reported and median reported screen time was around 2 $\mathrm{h}$, an estimate that is lower than the $2.7 \mathrm{~h}$ reported in the 2010 American Time Use Survey. Thus, underreporting of the amount of screen time by the NHANES participants is a possibility. If participants tended to underreport the true amount of screen time, the hazard ratios in the present study may have been underreported if participants at increased risk for mortality were shifted into the referent group thus raising the baseline risk of the referent group.

With 5.8 years of follow-up time, the duration of the present study is at the shorter end of the distribution, which ranges from 4.3 to 21 years. The study of 4.3 years found a significant association, whereas the study of 21 years did not. Consequently, it is unclear whether the duration of a study affects the chances of observing a significant result. As in virtually all observational studies, the results may have changed had additional known or unknown confounders been included in the analyses.

\section{Conclusion}

The amount of screen time did not significantly predict mortality from all-causes and diseases of the circulatory system in the present study. Nevertheless, the totality of the evidence from prospective studies continues to suggest that prolonged screen time adversely affects health. Because only a limited number of prospective studies have addressed the issue of whether screen time predicts mortality, additional such studies are needed to clarify and quantify any relationship.

Disclaimer: The findings and conclusions in this article are those of the author and do not necessarily represent the official position of the Centers for Disease Control and Prevention.

\section{Acknowledgements}

None.

\section{Author details}

Division of Adult and Community Health, National Center for Chronic Disease Prevention and Health Promotion, Centers for Disease Control and Prevention, Atlanta, GA, USA. ${ }^{2}$ Centers for Disease Control and Prevention, 4770 Buford Highway, MS K67, Atlanta, GA 30341, USA.

\section{Authors' contributions}

EF performed all work pertaining to this manuscript.

\section{Competing interests}

The author declares that they have no competing interests.

Received: 7 September 2011 Accepted: 23 January 2012 Published: 23 January 2012

\section{References}

1. Nielsen: Three Screen Report.[http://blog.nielsen.com/nielsenwire/ online_mobile/what-consumers-watch-nielsens-q1-2010-three-screen-report/ ].

2. U.S.Bureau of Labor Statistics: American Time Use Survey Summary.[http:// www.bls.gov/news.release/atus.nr0.htm].

3. Hu FB, Leitzmann MF, Stampfer MJ, Colditz GA, Willett WC, Rimm EB: Physical activity and television watching in relation to risk for type 2 diabetes mellitus in men. Arch Intern Med 2001, 161:1542-1548.

4. Hu FB, Li TY, Colditz GA, Willett WC, Manson JE: Television watching and other sedentary behaviors in relation to risk of obesity and type 2 diabetes mellitus in women. JAMA 2003, 289:1785-1791.

5. Dunstan DW, Salmon J, Owen N, Armstrong T, Zimmet PZ, Welborn TA, Cameron AJ, Dwyer T, Jolley D, Shaw JE: Physical activity and television viewing in relation to risk of undiagnosed abnormal glucose metabolism in adults. Diabetes Care 2004, 27:2603-2609.

6. Dunstan DW, Salmon J, Owen N, Armstrong T, Zimmet PZ, Welborn TA, Cameron AJ, Dwyer T, Jolley D, Shaw JE: Associations of TV viewing and physical activity with the metabolic syndrome in Australian adults. Diabetologia 2005, 48:2254-2261.

7. Ford ES, Kohl HW, Mokdad AH, Ajani UA: Sedentary behavior, physical activity, and the metabolic syndrome among U.S. adults. Obes Res 2005, 13:608-614.

8. Dunstan DW, Salmon J, Healy GN, Shaw JE, Jolley D, Zimmet PZ, Owen N: Association of television viewing with fasting and 2 -h postchallenge plasma glucose levels in adults without diagnosed diabetes. Diabetes Care 2007, 30:516-522. 
9. Healy GN, Dunstan DW, Salmon J, Shaw JE, Zimmet PZ, Owen N: Television time and continuous metabolic risk in physically active adults. Med Sci Sports Exerc 2008, 40:639-645.

10. Ford ES, Schulze MB, Kroger J, Pischon T, Bergmann MM, Boeing H: Television watching and incident diabetes: Findings from the European Prospective Investigation into Cancer and Nutrition-Potsdam Study. J Diabetes 2010, 2:23-27.

11. Ford ES, Li C, Zhao G, Pearson WS, Tsai J, Churilla JR: Sedentary behavior, physical activity, and concentrations of insulin among US adults. Metabolism 2010, 59:1268-1275.

12. U.S.Department of Health and Human Services: Healthy People 2020 Objective Topic Areas and Page Numbers.[http://www.healthypeople.gov/ 2020/topicsobjectives2020/pdfs/HP2020objectives.pdf].

13. Dunstan DW, Barr EL, Healy GN, Salmon J, Shaw JE, Balkau B, Magliano DJ, Cameron AJ, Zimmet PZ, Owen N: Television viewing time and mortality: the Australian Diabetes, Obesity and Lifestyle Study (AusDiab). Circulation 2010, 121:384-391.

14. Warren TY, Barry V, Hooker SP, Sui X, Church TS, Blair SN: Sedentary behaviors increase risk of cardiovascular disease mortality in men. Med Sci Sports Exerc 2010, 42:879-885.

15. Stamatakis E, Hamer M, Dunstan DW: Screen-based entertainment time, all-cause mortality, and cardiovascular events: population-based study with ongoing mortality and hospital events follow-up. J Am Coll Cardiol 2011, 57:292-299.

16. Wijndaele K, Brage S, Besson H, Khaw KT, Sharp SJ, Luben R, Wareham NJ, Ekelund U: Television viewing time independently predicts all-cause and cardiovascular mortality: the EPIC Norfolk Study. Int J Epidemiol 2011, 40:150-159.

17. Centers for Disease Control and Prevention: About the National Health and Nutrition Examination Survey.[http://www.cdc.gov/nchs/nhanes/ about_nhanes.htm].

18. Centers for Disease Control and Prevention: NHANES (1999-2004) Linked Mortality Files.[http://www.cdc.gov/nchs/data_access/data_linkage/ mortality/nhanes_99_04_linkage.htm].

19. Stampfer MJ, Willett WC, Speizer FE, Dysert DC, Lipnick R, Rosner B, Hennekens CH: Test of the National Death Index. Am J Epidemiol 1984, 119:837-839.

20. Edlavitch SA, Baxter J: Comparability of mortality follow-up before and after the National Death Index. Am J Epidemiol 1988, 127:1164-1178.

21. Calle EE, Terrell DD: Utility of the National Death Index for ascertainment of mortality among cancer prevention study II participants. Am J Epidemiol 1993, 137:235-241.

22. Kennedy ET, Ohls J, Carlson S, Fleming K: The Healthy Eating Index: design and applications. J Am Diet Assoc 1995, 95:1103-1108.

23. Grontved A, Hu FB: Television viewing and risk of type 2 diabetes, cardiovascular disease, and all-cause mortality: a meta-analysis. JAMA 2011, 305:2448-2455.

24. Inoue M, Iso H, Yamamoto S, Kurahashi N, Iwasaki M, Sasazuki S, Tsugane S: Daily total physical activity level and premature death in men and women: results from a large-scale population-based cohort study in Japan (JPHC study). Ann Epidemiol 2008, 18:522-530.

25. Katzmarzyk PT, Church TS, Craig CL, Bouchard C: Sitting time and mortality from all causes, cardiovascular disease, and cancer. Med Sci Sports Exerc 2009, 41:998-1005.

26. Patel AV, Bernstein L, Deka A, Feigelson HS, Campbell PT, Gapstur SM, Colditz GA, Thun MJ: Leisure time spent sitting in relation to total mortality in a prospective cohort of US adults. Am J Epidemiol 2010, 172:419-429.

27. Clark BK, Sugiyama T, Healy GN, Salmon J, Dunstan DW, Owen N: Validity and reliability of measures of television viewing time and other nonoccupational sedentary behaviour of adults: a review. Obes Rev 2009, 10:7-16

\section{Pre-publication history}

The pre-publication history for this paper can be accessed here: http://www.biomedcentral.com/1471-2458/12/70/prepub

\footnotetext{
doi:10.1186/1471-2458-12-70

Cite this article as: Ford: Combined television viewing and computer use and mortality from all-causes and diseases of the circulatory system among adults in the United States. BMC Public Health 2012 12:70.
}

\section{Submit your next manuscript to BioMed Central and take full advantage of:}

- Convenient online submission

- Thorough peer review

- No space constraints or color figure charges

- Immediate publication on acceptance

- Inclusion in PubMed, CAS, Scopus and Google Scholar

- Research which is freely available for redistribution 